BMJ Open

Diabetes

Research

\& Care

\title{
Stages of change for physical activity and dietary habits in persons with type 2 diabetes included in a mobile health intervention: the Norwegian study in RENEWING HEALTH
}

\author{
Heidi Holmen, ${ }^{1,2}$ Astrid Wahl, ${ }^{2}$ Astrid Torbjørnsen, ${ }^{1,3}$ Anne Karen Jenum, ${ }^{3}$ \\ Milada Cvancarova Småstuen, ${ }^{1}$ Lis Ribu ${ }^{1}$
}

To cite: Holmen $\mathrm{H}$, Wahl A, Torbjørnsen A, et al. Stages of change for physical activity and dietary habits in persons with type 2 diabetes included in a mobile health intervention: the Norwegian study in RENEWING HEALTH. BMJ Open Diabetes Research and Care 2016;4:e000193. doi:10.1136/bmjdrc-2016000193

\section{- Additional material is} available. To view please visit the journal (http://dx.doi.org/ 10.1136/bmjdrc-2016000193)

Portions of this study were presented in a poster at the 20th Annual Conference of International Society for Quality of Life Research (ISOQOL), Miami, Florida, 9-12 October 2013.

Received 7 January 2016 Revised 24 February 2016 Accepted 2 April 2016

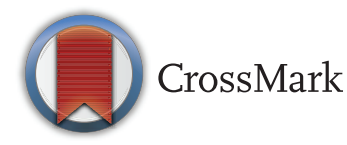

For numbered affiliations see end of article.

Correspondence to Dr Heidi Holmen; Heidi.holmen@hioa.no

\section{ABSTRACT}

Objective: The aim of this study was to investigate stages of change for physical activity and dietary habits using baseline data from persons with type 2 diabetes included in a mobile health intervention. We examined the associations between stages of change for physical activity change and dietary change, and between stages of change for each behavior and individual characteristics, health-related quality of life, selfmanagement, depressive symptoms, and lifestyle.

Research design and methods: We examined 151 persons with type 2 diabetes with an glycated hemoglobin ( $\mathrm{HbA1c}$ ) level $\geq 7.1 \%$, aged $\geq 18$ years at baseline of a randomized controlled trial, before testing a mobile app with or without health counseling. Stages of change were dichotomized into 'pre-action' and 'action'. Self-management was measured using the Health Education Impact Questionnaire (heiQ) where a higher score reflects increased self-management, and healthrelated quality of life was measured with the Short-Form36 (SF-36). Logistic regression modeling was performed. Results: The median HbA1c level was 7.9\% (7.112.4), $90 \%$ were overweight or obese, and $20 \%$ had $\geq 3$ comorbidities. $58 \%$ were in the preaction stage for physical activity change and $79 \%$ in the preaction stage for dietary change. Higher scores of selfmanagement were associated with an increased chance of being in the action stage for both dietary change and physical activity change. Higher body mass index was associated with an $8 \%$ reduced chance of being in the action stage for physical activity change (OR 0.92 , $95 \% \mathrm{Cl} 0.86$ to 0.99 ).

Conclusions: Being in the action stage was associated with higher scores of self-management, crucial for type 2 diabetes. Over half of the participants were in the preaction stage for physical activity and dietary change, and many had a high disease burden with comorbidities and overweight.

Trial registration number: NCT01315756.

\section{INTRODUCTION}

Living with type 2 diabetes is associated with deteriorating health-related quality of life

\section{Key messages}

Stages of change may be valuable when assessing characteristics of persons engaging in an intervention for behavior change.

- The participants voluntarily engaging in our mobile health study had a high disease burden with co-morbidities and overweight.

- Over half of our participants were in the preaction stage for physical activity change and dietary change, meaning that they were not currently in a behavior change process.

- Being in the action stage for physical activity change and dietary change was independently associated with higher scores of selfmanagement, crucial for diabetes.

(HRQL) and increased symptoms of depression. ${ }^{1-3}$ Diabetes self-management support to encourage physical activity, a healthy diet, and medication adherence is the cornerstone of treatment to achieve good glycemic control. ${ }^{145} \mathrm{HRQL}$ and glycemic control are often associated and both are important for persons with type 2 diabetes. $^{3}$ Further, poorer HRQL is also associated with an increased risk of mortality and inability to work in persons with diabetes. ${ }^{6}$

One reason that some people succeed with lifestyle changes may relate to their stage of change in the particular behavior. The transtheoretical model (TTM) stages of change describe the process individuals may go through when trying to achieve lifestyle changes. ${ }^{78}$ The five stages are precontemplation, contemplation, preparation, action, and maintenance. Linear progression is rare, and relapse and recycling through the stages may occur when trying to reach the maintenance stage. Further, earlier research has found a positive association between stages of change in different behaviors. ${ }^{9}$ The model seems 
relevant for diabetes management. ${ }^{8}$ Stages of change in lifestyle, such as adopting a healthy diet, ${ }^{9-14}$ being physically active and self-monitoring blood glucose level, ${ }^{9} 15$ have been investigated in persons with diabetes. A higher stage of change in dietary habits is associated with being female and married, and with older age. ${ }^{10}$ An association has also been found between being in the action stage for dietary change and having poor HRQL, and between being in the maintenance stage and having a good HRQL. ${ }^{10}$ However, HRQL is rarely evaluated in studies that have applied the stages of change model. ${ }^{16} \mathrm{~A}$ review using the stages of change model in diabetes management found that moving up through the stages was associated with increased glycemic control, ${ }^{16}$ and a meta-analysis provide evidence on the effectiveness of tailoring health behavior messages to the stages of change with several variables also moderating this effect. ${ }^{17}$ However, owing to the inconclusive findings of previous studies, more research within this area is needed. ${ }^{12} 16$

Lifestyle interventions for persons with type 2 diabetes are frequently reported; most interventions aim for lifestyle changes and increased self-management, and have been used for glycemic control, ${ }^{18}$ participation in exercise to improve glycemic control, ${ }^{19}$ and improved HRQL. ${ }^{3}$ A recent trend in diabetes self-management support includes mobile health (mHealth), which is now possible because of the rapid evolution of smartphones and the use of data tracking and reminders. However, reviews have concluded that the effects of mHealth remain uncertain, because of the heterogeneity of the included studies. ${ }^{20}{ }^{21}$ To the best of our knowledge, the associations between stages of change and the two most important lifestyle factors, physical activity and dietary habits, in persons with type 2 diabetes taking part in mHealth lifestyle interventions have not been explored. In the Norwegian three-armed randomized controlled trial (RCT) RENEWING HEALTH, a significant effect of the mHealth intervention was not found because all three groups exhibited a decreased glycated hemoglobin (HbAlc) level and there were no differences between the groups. ${ }^{22} 23$ The participants' stages of change in physical activity and dietary habits were assessed at baseline using the stages of change model. On the basis of the inconclusive findings in the mHealth intervention study, and the knowledge that stages of change may be important in a lifestyle change process, we investigated the participants' characteristics to elaborate our understanding about how to tailor interventions to the participants' stages of change in the future.

The aim of this study was to investigate stages of change for physical activity and dietary habits using baseline data from persons with type 2 diabetes included in a mobile health intervention. We examined the associations between stages of change for physical activity change and dietary change, and between stages of change for each behavior and individual characteristics, health-related quality of life, self-management, depressive symptoms, and lifestyle.

\section{RESEARCH DESIGN AND METHODS}

\section{Study design}

The current study was part of a large European Union (EU) collaboration initiated in 2010 involving telehealth interventions in nine European countries. The Norwegian Study in RENEWING HEALTH (REgioNs of Europe WorkING together for HEALTH) was an RCT with three study arms that randomized persons with type 2 diabetes into one of two intervention groups or a control group. The protocol and main results are described elsewhere. ${ }^{22-24}$ In this article, we report the results based exclusively on baseline data from the trial.

\section{Setting and participants}

All participants lived in their homes and most were recruited from the southern and northern parts of Norway through their general practitioner (GP) and other healthcare personnel. Some of those who were newly diagnosed with type 2 diabetes were recruited through specialist healthcare courses and, in addition, some were recruited through advertisement in the Norwegian Diabetes Associations media. Participants were eligible if they had an HbAlc level $\geq 7.1 \%$ ( $54 \mathrm{mmol} / \mathrm{mol}$ ), were $\geq 18$ years of age, and were able to complete questionnaires in Norwegian. They had to be able to use a smartphone. ${ }^{24}$ We assessed 298 persons for eligibility. Of these, 82 did not meet the inclusion criteria (65 had an HbAlc level below the threshold) and 52 declined to participate. After randomization, 12 of the remaining 164 persons were excluded because their HbAlc level was measured as being below the threshold of $7.1 \%(54 \mathrm{mmol} / \mathrm{mol})$, and one control group participant withdrew consent. A total of 151 participants were included from March 2011 to October 2012.

\section{Measures}

Demographics were self-reported and included age, gender, marital status, education, and employment status, and were collected in accordance with the data set standard of the EU collaboration project. ${ }^{24} 25$ Clinical measures and disease-specific data regarding medication, laboratory status (including HbAlc level, height, weight, and blood pressure), and late complications were obtained from the GPs. Comorbidities, year and cause of diagnosis, and history of eye problems, foot ulcers, and amputations were self-reported.

Stages of change in physical activity ${ }^{26}$ were measured by the one-item question developed by Prochaska and Marcus $^{27}$ using a five-point Likert response scale for stages of change. On the basis of earlier research, we constructed a 'preaction' and 'action' dichotomy in which the preaction stage comprised the 'precontemplation', 'contemplation', and 'preparation' stages, and the 
action stage comprised the stages of 'action' and 'maintenance'. ${ }^{10}$ Physical activity levels were measured using a questionnaire from the Norwegian study HUNT $3^{28}$ and, based on earlier research, we have constructed a dichotomous variable 'physically inactive' and 'physically active' based on the frequency, duration, and intensity of their physical activity. ${ }^{29}$

Stages of change in dietary habits were measured using a five-point Likert scale with responses to 'eating as recommended'. The variable for stages of change in diet was dichotomized into 'pre-action' and 'action' stages using the combinations described above for the physical activity variable. ${ }^{10}$ Dietary habits were measured using a questionnaire based on recommended food items measuring traditional Norwegian dietary habits. ${ }^{30}$ In the present paper, we report a selection of these variables (poultry, meat, fish, chocolate, and greens) where the responses are dichotomized based on $>3$ servings per month for all, except for greens, which is a mean score of daily average intake of greens.

HRQL was measured using the Short Form 36 Health Survey (V.2) (SF-36), which contains 36 items forming eight conceptual domains within physical and mental health: physical functioning, role physical, bodily pain, general health, vitality, social functioning, role emotional, and mental health. ${ }^{31}$ The scores for the eight domains are summed to form a physical component score (PCS) and a mental component score (MCS). Scores range from 0 to 100 , with higher scores indicating higher HRQL, also for bodily pain were a higher score indicate less pain or limitations due to pain. The SF-36 V.1 has been translated and validated in a Norwegian setting. ${ }^{32}$

The Health Education Impact Questionnaire (heiQ) is used to evaluate self-management, and contains 40 questions grouped into eight domains. ${ }^{33}$ Higher scores reflect greater self-management. Responses are made using four-point Likert scales ranging from 'strongly agree' to 'strongly disagree,' and the items are summed and divided to form the eight domains: positive and active engagement in life, health-directed activity, skill and technique acquisition, constructive attitude and approaches, self-monitoring and insight, health service navigation, social integration and support; and emotional well-being (reversed scale). The heiQ is used in various languages, ${ }^{34}$ and has been translated into Norwegian.

Depressive symptoms were assessed using The Center for Epidemiologic Studies Depression scale (CES-D), which contains 20 questions. The behavioral, cognitive, and affective symptoms of depression are scored and range from 0 (rarely or none of the time) to 3 (most or all of the time), with total possible scores ranging from 0 to 60. CES-D scores were also analyzed as a categorical variable dichotomized at the cut-off with scores $\geq 16$ representing depressive symptoms. It is highly reliable, with high concurrent and construct validity, ${ }^{35}$ and has been used in diabetes populations. ${ }^{2}$

\section{Ethical considerations}

The study was approved by the Regional Ethics Committee South East in Norway, and healthcare personnel handed out an information sheet about the study and recruited the participants to a meeting with the researchers for more information. Informed consent was obtained by the researchers from all participants after detailed written and verbal information was provided regarding the study and its procedures. ${ }^{24}$

\section{Statistical analysis}

Most of the continuous variables were not normally distributed and therefore are described as medians with minimum-maximum values, and categorical data are presented as proportions and percentages. Crude associations between pairs of continuous variables were assessed using the non-parametric Mann-Whitney $\mathrm{U}$ test for skewed and ranked data, and the $\chi^{2}$ test was used to compare pairs of categorical data. Associations between a binary outcome (dependent) and selected covariates were modeled using logistic regression. We fit two sets of models: one for stages of change in physical activity and one for stages of change in dietary habits as the dependent grouping variables. First, we fitted univariate logistic regressions for each of the domains of the heiQ the SF-36, the CES-D, and the lifestyle variables; second, we entered each score separately into a multiple logistic regression one by one. To adjust for possible confounders, we included age, gender, and educational level in the final models (separate model for each domain). Owing to the exploratory nature of our study, we did not correct for multiple testing, and $p$ values $<0.05$ were considered statistically significant. All tests were two-sided. All analyses were performed using SPSS V.21.

\section{RESULTS}

\section{Sample characteristics}

The demographic, clinical, and treatment characteristics for the whole sample and for participants in the preaction and action stages for physical activity and dietary changes are presented in table 1 . In the complete sample, the included participants were middle-aged with a median age of 58 years (minimum-maximum 20-80), $89(59 \%)$ were male, $51(34 \%)$ had higher education (>12 years), and more than half were currently working $(\mathrm{n}=79 ; 53 \%)$. Metabolic control was reflected by a median HbAlc level of $7.9 \%$ ((7.1-12.4\%) $63 \mathrm{mmol} /$ mol (54-112)), and 116 (90\%) had a body mass index (BMI) categorized as overweight to obese class III (BMI $>25 \mathrm{~kg} / \mathrm{m}^{2}$ ). The median duration of type 2 diabetes was 9 years (1-36) and 30 (20\%) had three or more comorbidities. Twenty-four (16\%) reported that they currently smoked (table 2 ).

We found no significant differences between the preaction and action groups, except for BMI, which was significantly higher for those in the preaction stage compared with the action stage for physical activity change. 
Table 1 Demographic and clinical variables, number (\%), and median (minimum-maximum)

\begin{tabular}{|c|c|c|c|c|c|c|}
\hline & \multicolumn{2}{|c|}{ Total $\mathrm{N}=151$} & \multicolumn{2}{|c|}{ Physical activity $\mathrm{N}=151$} & \multicolumn{2}{|c|}{ Dietary changes $N=150$} \\
\hline & $\mathbf{N}$ & & $\begin{array}{l}\text { Preaction } \\
\mathrm{n}=\mathbf{8 8}\end{array}$ & $\begin{array}{l}\text { Action } \\
n=63\end{array}$ & $\begin{array}{l}\text { Preaction } \\
\mathrm{n}=119\end{array}$ & $\begin{array}{l}\text { Action } \\
\mathrm{n}=31\end{array}$ \\
\hline \multicolumn{7}{|l|}{ Demographic variables } \\
\hline Age, years & 151 & $58(20-80)$ & $57(29-80)$ & $61(20-79)$ & $58(20-80)$ & $60(29-78)$ \\
\hline Gender, male & 151 & $89(59)$ & $49(56)$ & $40(64)$ & $73(61)$ & $15(48)$ \\
\hline Education (years) ${ }^{\star}$ & 151 & & & & & \\
\hline$<12$ & & $83(55)$ & $47(53)$ & $36(57)$ & $65(55)$ & $17(55)$ \\
\hline 12 & & $17(11)$ & $12(14)$ & $5(8)$ & $13(11)$ & $4(13)$ \\
\hline$>12$ & & $51(34)$ & $29(33)$ & $22(35)$ & $41(34)$ & $10(32)$ \\
\hline Employment status $†$ & 148 & & & & & \\
\hline Employed & & $79(53)$ & $43(50)$ & $36(58)$ & $66(57)$ & $13(42)$ \\
\hline Unemployed & & $41(28)$ & $27(31)$ & $14(23)$ & $27(23)$ & $14(45)$ \\
\hline Retired & & 28 (19) & $16(19)$ & 12 (19) & $23(20)$ & $4(13)$ \\
\hline $\begin{array}{l}\text { Cohabitation, cohabiting } \\
\text { Clinical variables }\end{array}$ & 151 & $110(73)$ & $65(74)$ & $45(71)$ & $88(74)$ & $21(68)$ \\
\hline Duration of diabetes, years & 138 & $9(1-36)$ & $10(1-34)$ & $8(1-36)$ & $9(1-34)$ & $11(1-36)$ \\
\hline $\mathrm{HbA1c}, \%$ & 151 & $7.9(7.1-12.4)$ & $7.9(7.1-12.4)$ & $7.8(7.1-11.6)$ & $7.9(7.1-12.4)$ & $7.7(7.1-10.3)$ \\
\hline $\mathrm{HbA} 1 \mathrm{c}, \mathrm{mmol} / \mathrm{mol}$ & 151 & $63(54-112)$ & $63(54-112)$ & $62(54-103)$ & $63(54-112)$ & $61(54-89)$ \\
\hline Systolic blood pressure, $\mathrm{mm} \mathrm{Hg}$ & 120 & $134(100-182)$ & $130(100-182)$ & $135(100-182)$ & $134(100-182)$ & $132(100-159)$ \\
\hline $\mathrm{BMI}, \mathrm{kg} / \mathrm{m}^{2}$ & 129 & $31(20-53)$ & $33(24-53) \S$ & $30(20-53) \S$ & $31(20-53)$ & $30(21-44)$ \\
\hline Normalף & & $13(10)$ & $4(6)$ & $9(16)$ & $8(8)$ & $5(19)$ \\
\hline Overweight & & $41(32)$ & $21(29)$ & $20(35)$ & $32(31)$ & $8(31)$ \\
\hline Obese class I & & $42(33)$ & $25(35)$ & $17(30)$ & $34(33)$ & $8(31)$ \\
\hline Obese class II & & $20(16)$ & $12(17)$ & $8(14)$ & $18(18)$ & $2(8)$ \\
\hline Obese class III & & $13(10)$ & $10(14)$ & $3(5)$ & $10(10)$ & $3(12)$ \\
\hline Comorbidities & 151 & & & & & \\
\hline 0 & & $24(16)$ & $10(11)$ & $14(22)$ & $16(13)$ & $8(26)$ \\
\hline $1-2$ & & $97(64)$ & $56(64)$ & $41(65)$ & $81(68)$ & $16(52)$ \\
\hline 3 or more & & $30(20)$ & $22(25)$ & $8(13)$ & 22 (19) & 7 (23) \\
\hline Late complication-eye & 151 & $19(13)$ & $10(11)$ & $9(14)$ & $12(10)$ & 7 (23) \\
\hline $\begin{array}{l}\text { Late complication-foot ulcer } \\
\text { Treatment variable }\end{array}$ & 151 & $23(15)$ & $17(19)$ & $6(10)$ & $20(17)$ & $3(10)$ \\
\hline Medication regime & 131 & & & & & \\
\hline No medication & & $9(7)$ & $3(4)$ & $6(11)$ & $7(7)$ & $2(8)$ \\
\hline Oral agents only & & $63(48)$ & $41(55)$ & 22 (39) & $54(52)$ & $9(35)$ \\
\hline Injections only** & & $19(15)$ & $10(14)$ & $9(16)$ & $13(13)$ & 5 (19) \\
\hline $\begin{array}{l}\text { Combination of oral agents and } \\
\text { injections }\end{array}$ & & $40(31)$ & $20(27)$ & $20(35)$ & $30(29)$ & $10(39)$ \\
\hline $\begin{array}{l}\text { Self-monitoring of blood } \\
\text { glucose, yes }\end{array}$ & 151 & $142(94)$ & $83(94)$ & $59(94)$ & $112(94)$ & $29(94)$ \\
\hline \multicolumn{7}{|c|}{ 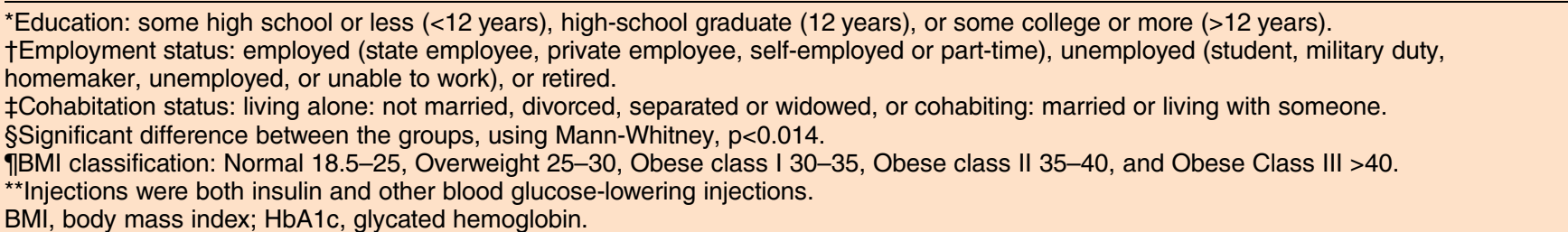 } \\
\hline
\end{tabular}

\section{Stages of change}

When stages of change were dichotomized for physical activity, $88(58 \%)$ participants were in the preaction stage, and $63(42 \%)$ were in the action stage (table 3 ). For dietary change, $119(79 \%)$ were in the preaction stage, and $31(21 \%)$ were in the action stage.

There was a significant association between the dichotomized stages in physical activity change and dietary change, where $75(85 \%)$ of those in the preaction stage for physical activity change also reported being in the preaction stage for dietary change. More than half of those in the action stage for physical activity change reported being in the action stage for dietary change $(\mathrm{n}=31,58 \%)$. These associations remained significant after adjusting for age, gender, and educational level. Those who were in the action stage for dietary change were more than twice as likely to be in the action stage for physical activity change (OR=2.5, 95\% CI 1.10 to 
Table 2 Lifestyle variables, number (\%), and median (minimum-maximum)

\begin{tabular}{|c|c|c|c|c|c|c|}
\hline & \multirow{2}{*}{$\begin{array}{l}\text { Total } \\
\mathbf{N} \\
\end{array}$} & & \multicolumn{2}{|c|}{ Physical activity } & \multicolumn{2}{|c|}{ Dietary changes } \\
\hline & & & Preaction & Action & Preaction & Action \\
\hline Smoking, yes & 151 & $24(16)$ & $17(19)$ & $7(11)$ & $21(18)$ & $3(10)$ \\
\hline Alcohol & 144 & & & & & \\
\hline Less than monthly or never & & $74(51)$ & $47(56)$ & $27(45)$ & $62(53)$ & $12(43)$ \\
\hline 1-3 times per month & & $\begin{array}{l}37(26) \\
-\end{array}$ & $22(26)$ & $15(25)$ & $27(23)$ & $10(36)$ \\
\hline Weekly & & $33(23)$ & $15(18)$ & $18(30)$ & $27(23)$ & $6(21)$ \\
\hline Physical Activity, physically active* & 149 & $51(34)$ & $10(12)$ & $41(65)$ & $38(33)$ & $13(42)$ \\
\hline Diet change past year (yes) & 151 & $68(45)$ & $40(46)$ & $28(44)$ & 48 (40)† & $19(61) \dagger$ \\
\hline Poultry $>3$ servings per month & 146 & $87(60)$ & $51(60)$ & $36(59)$ & $68(59)$ & $18(62)$ \\
\hline Meat $>3$ servings per month & 143 & $129(90)$ & $76(92)$ & $53(88)$ & $103(90)$ & $25(89)$ \\
\hline Fish $>3$ servings per month & 148 & $116(78)$ & $65(75)$ & $51(84)$ & $88(75)$ & $27(90)$ \\
\hline Chocolate $>3$ servings per month & 148 & $68(46)$ & $44(51)$ & $24(39)$ & $57(48)$ & $11(37)$ \\
\hline Daily servings of greens $\ddagger$ & 148 & $2.8(0.1-12.0)$ & $2.5(0.1-12.0)$ & $2.8(0.9-10.5)$ & $2.4(0.1-10.5)$ & $3.8(0.9-12.0)$ \\
\hline
\end{tabular}

5.88; table 4). Age, gender, and educational level were not significantly associated with the stage of change for dietary or physical activity habits.

\section{Self-management and stages of change}

Higher scores on the items health-directed activity, positive and active engagement in life, and constructive attitude and approaches were related to an increased chance of being in the action stage for physical activity change after adjusting for age, gender, and educational level (table 4). Higher scores on skill and technique acquisition, social integration and support, and health service navigation were related to an increased chance of being in the action stage for physical activity change. Higher scores on health-directed activity, self-monitoring and insight, skill and technique acquisition, and health service navigation were related to an increased probability of being in the action stage for dietary change (table 4). These findings are also visualized in figure 1 , and the descriptive information is found in online supplementary appendix table 1 .

\section{HRQL and stages of change}

Higher scores on physical functioning, role physical, bodily pain, and general health were related to an increased chance of being in the action stage for physical activity change after adjusting for age, gender, and educational level (table 4 and figure 1). With an increase in the PCS, participants were more likely to be in the action stage compared with the preaction stage ( $\mathrm{OR}=1.17,95 \%$ CI 1.06 to 1.29). Further, higher scores on vitality, social functioning, and mental health were associated with an increased chance of being in the action stage for physical activity change. Higher scores on the MCS of the SF-36 were associated with lower odds of being in the action stage for dietary change compared to the preaction stage ( $\mathrm{OR}=0.96,95 \%$ CI 0.92 to 0.99 ).

\section{Lifestyle variables}

Each unit increase in BMI was associated with an $8 \%$ reduced chance of being in the action stage for physical activity change after adjusting for age, gender, and educational level (table 4).

Table 3 Stages of change in physical activity and dietary habits, divided into five and two stages

\begin{tabular}{|c|c|c|c|c|c|}
\hline & $\mathbf{N}$ & 5 stages & $\mathbf{N}(\%)$ & 2 stages & N (\%) \\
\hline Physical activity & 151 & $\begin{array}{l}\text { Precontemplation } \\
\text { Contemplation } \\
\text { Preparation }\end{array}$ & $\begin{array}{c}5(3) \\
37(25) \\
46(31)\end{array}$ & Preaction & $88(58)$ \\
\hline & & $\begin{array}{l}\text { Action } \\
\text { Maintenance }\end{array}$ & $\begin{array}{l}22(15) \\
41(27)\end{array}$ & Action & $63(42)$ \\
\hline Dietary habits & 150 & $\begin{array}{l}\text { Precontemplation } \\
\text { Contemplation } \\
\text { Preparation } \\
\text { Action } \\
\text { Maintenance }\end{array}$ & $\begin{aligned} 7 & (5) \\
32 & (21) \\
80 & (53) \\
9 & (6) \\
22 & (15)\end{aligned}$ & $\begin{array}{l}\text { Preaction } \\
\text { Action }\end{array}$ & $\begin{array}{r}119(79) \\
31(21)\end{array}$ \\
\hline
\end{tabular}


Table 4 Unadjusted and adjusted ORs for stages of change in physical activity and dietary habits as the dependent variable

\begin{tabular}{|c|c|c|c|c|c|c|}
\hline Variable & Unadjusted OR & $95 \% \mathrm{Cl}$ & p Value & Adjusted OR ${ }^{\star}$ & $95 \% \mathrm{Cl}$ & p Value \\
\hline \multicolumn{7}{|c|}{$\begin{array}{l}\text { Stage of change in physical activity as dependent } \\
\text { TTM stage of change in dietary changes }\end{array}$} \\
\hline 1. Preaction (ref) & 1 & - & - & 1 & - & - \\
\hline Action & 2.38 & $1.05-5.26$ & $0.036 \dagger$ & 2.50 & $1.10-5.88$ & $0.028 \dagger$ \\
\hline \multicolumn{7}{|l|}{ Clinical variable } \\
\hline $\mathrm{BMI}$ & 0.92 & $0.86-0.98$ & $0.011 \dagger$ & 0.92 & $0.86-0.99$ & $0.019 \dagger$ \\
\hline \multicolumn{7}{|l|}{ SF-36 } \\
\hline Physical functioning & 1.03 & $1.01-1.05$ & $0.005 \uparrow$ & 1.03 & $1.01-1.05$ & $0.002 \dagger$ \\
\hline Role physical & 1.01 & $1.00-1.02$ & $0.046 \dagger$ & 1.01 & $1.00-1.03$ & $0.030 \dagger$ \\
\hline Bodily pain & 1.02 & $1.00-1.03$ & $0.009 \dagger$ & 1.02 & $1.00-1.03$ & $0.010 \dagger$ \\
\hline General health & 1.02 & $1.01-1.04$ & $0.004 \dagger$ & 1.02 & $1.01-1.04$ & $0.005 \dagger$ \\
\hline Vitality & 1.04 & $1.01-1.06$ & $0.001 \dagger$ & 1.04 & $1.01-1.06$ & $0.002 \dagger$ \\
\hline Social functioning & 1.02 & $1.01-1.04$ & $0.006 \dagger$ & 1.02 & $1.01-1.04$ & $0.007 \dagger$ \\
\hline Role emotional & 1.01 & $0.99-1.03$ & 0.094 & 1.01 & $0.99-1.03$ & 0.072 \\
\hline Mental health & 1.04 & $1.01-1.07$ & $0.005+$ & 1.04 & $1.01-1.07$ & $0.008 \dagger$ \\
\hline PCS & 1.14 & $1.04-1.24$ & $0.005 \dagger$ & 1.17 & $1.06-1.29$ & $0.002 \dagger$ \\
\hline MCS & 1.04 & $1.00-1.08$ & $0.049 \dagger$ & 1.04 & $0.99-1.08$ & 0.072 \\
\hline \multicolumn{7}{|l|}{ heiQ } \\
\hline Health-directed activity & 13.4 & $5.36-33.49$ & $<0.001 \dagger$ & 14.6 & $5.69-37.49$ & $<0.001 \dagger$ \\
\hline Positive and active engagement in life & 3.49 & $1.57-7.72$ & $0.002 \dagger$ & 4.08 & $1.75-9.53$ & $0.001 \dagger$ \\
\hline Emotional distress & 1.65 & $0.99-2.73$ & 0.052 & 1.67 & $0.98-2.81$ & 0.055 \\
\hline Self-monitoring and insight & 2.53 & $0.94-6.82$ & 0.065 & 2.53 & $0.92-6.96$ & 0.072 \\
\hline Constructive attitude and approaches & 2.38 & $1.24-4.57$ & $0.009+$ & 2.73 & $1.37-5.45$ & $0.004 \dagger$ \\
\hline Skill and technique acquisition & 3.77 & $1.53-9.28$ & $0.004 \dagger$ & 4.50 & $1.77-11.43$ & $0.002 \dagger$ \\
\hline Social integration and support & 2.78 & $1.45-5.32$ & $0.002 \dagger$ & 2.86 & $1.47-5.55$ & $0.002 \dagger$ \\
\hline Health service navigation & 2.64 & $1.29-5.39$ & $0.008+$ & 2.64 & $1.27-5.45$ & $0.009+$ \\
\hline \multicolumn{7}{|l|}{ CES-D } \\
\hline$<16$ & 2.78 & $1.16-6.65$ & $0.022 \dagger$ & 2.86 & $1.17-7.01$ & $0.022 \dagger$ \\
\hline$\geq 16$ (ref) & 1 & - & - & 1 & - & - \\
\hline \multicolumn{7}{|l|}{ Physical activity } \\
\hline Physically inactive (ref) & 1 & - & - & - & - & - \\
\hline Physically active & 14.29 & $6.25-33.34$ & $<0.001 \dagger$ & 16.67 & 6.67-33.34 & $<0.001 \dagger$ \\
\hline \multicolumn{7}{|c|}{$\begin{array}{l}\text { Stage of change in dietary habits as dependent } \\
\text { TTM stages of change in physical activity }\end{array}$} \\
\hline Preaction (ref) & 1 & - & - & - & - & - \\
\hline Action & 2.38 & $1.05-5.26$ & $0.036 \dagger$ & 2.50 & $1.10-5.88$ & $0.028 \dagger$ \\
\hline \multicolumn{7}{|l|}{ SF-36 } \\
\hline Physical functioning & 1.02 & $0.99-1.04$ & 0.181 & 1.02 & $0.98-1.05$ & 0.404 \\
\hline Role physical & 1.00 & $0.99-1.01$ & 0.936 & 1.00 & $0.99-1.02$ & 0.805 \\
\hline Bodily pain & 1.00 & $0.99-1.02$ & 0.763 & 1.00 & $0.99-1.02$ & 0.735 \\
\hline General health & 1.01 & $0.99-1.03$ & 0.303 & 1.01 & $0.99-1.03$ & 0.277 \\
\hline
\end{tabular}




\begin{tabular}{|c|c|c|c|c|c|c|}
\hline Variable & Unadjusted OR & $95 \% \mathrm{Cl}$ & p Value & Adjusted OR* & $95 \% \mathrm{Cl}$ & p Value \\
\hline Vitality & 1.00 & $0.98-1.03$ & 0.817 & 1.00 & $0.98-1.03$ & 0.734 \\
\hline Social functioning & 0.99 & $0.98-1.01$ & 0.218 & 0.99 & $0.98-1.01$ & 0.290 \\
\hline Role emotional & 0.99 & $0.97-1.01$ & 0.236 & 0.99 & $0.98-1.01$ & 0.287 \\
\hline Mental health & 0.98 & $0.96-1.01$ & 0.184 & 0.98 & $0.96-1.01$ & 0.168 \\
\hline PCS & 1.02 & $0.97-1.20$ & 0.181 & 1.01 & $0.99-1.24$ & 0.088 \\
\hline MCS & 0.96 & $0.93-0.99$ & 0.043† & 0.96 & $0.92-0.99$ & $0.039 \dagger$ \\
\hline \multicolumn{7}{|l|}{ heiQ } \\
\hline Health-directed activity & 1.19 & $1.02-1.38$ & $0.024 \dagger$ & 1.19 & $1.02-1.38$ & $0.026 \dagger$ \\
\hline Positive and active engagement in life & 1.28 & $0.56-2.93$ & 0.561 & 1.33 & $0.57-3.11$ & 0.509 \\
\hline Emotional distress & 1.09 & $0.60-1.98$ & 0.765 & 1.01 & $0.97-1.04$ & 0.748 \\
\hline Self-monitoring and insight & 7.74 & $2.14-28.04$ & $0.002 \dagger$ & 7.72 & $2.09-28.60$ & $0.002 \dagger$ \\
\hline Constructive attitudes and approaches & 1.20 & $0.56-2.53$ & 0.641 & 1.18 & $0.54-2.54$ & 0.683 \\
\hline Skill and technique acquisition & 3.68 & $1.34-10.15$ & $0.012 \dagger$ & 3.74 & $1.32-10.64$ & $0.013 \dagger$ \\
\hline Social integration and support & 1.10 & $0.54-2.22$ & 0.799 & 1.01 & $0.97-1.04$ & 0.727 \\
\hline Health service navigation & 2.43 & $1.03-5.70$ & $0.042 \dagger$ & 2.52 & $1.05-6.02$ & $0.038+$ \\
\hline \multicolumn{7}{|l|}{ CES-D } \\
\hline$<16$ & 0.63 & $0.26-1.54$ & 0.308 & 0.58 & $0.23-1.48$ & 0.254 \\
\hline$\geq 16$ (ref) & 1 & - & - & 1 & - & - \\
\hline \multicolumn{7}{|l|}{ Diet } \\
\hline Daily average intake of greens & 1.27 & $1.06-1.52$ & $0.009 \dagger$ & 1.27 & $1.05-1.54$ & $0.012 \dagger$ \\
\hline \multicolumn{7}{|l|}{ Diet change past year } \\
\hline No change & 0.42 & $0.19-0.96$ & $0.040 \dagger$ & 0.37 & $0.16-0.89$ & $0.026 \dagger$ \\
\hline Change (ref) & 1 & - & - & 1 & - & - \\
\hline
\end{tabular}

${ }^{\star}$ Adjusted for age, gender, and education using Multiple Logistic Regression.

†Statistically significant, $\mathrm{p}<0.05$.

BMI, body mass index; CES-D, Center for Epidemiologic Studies Depression scale; heiQ, Health Education Impact Questionnaire; MCS, mental component score; PCS, physical component score; SF-36, short form 36; TTM, The Transtheoretical Model Stages of Change. 

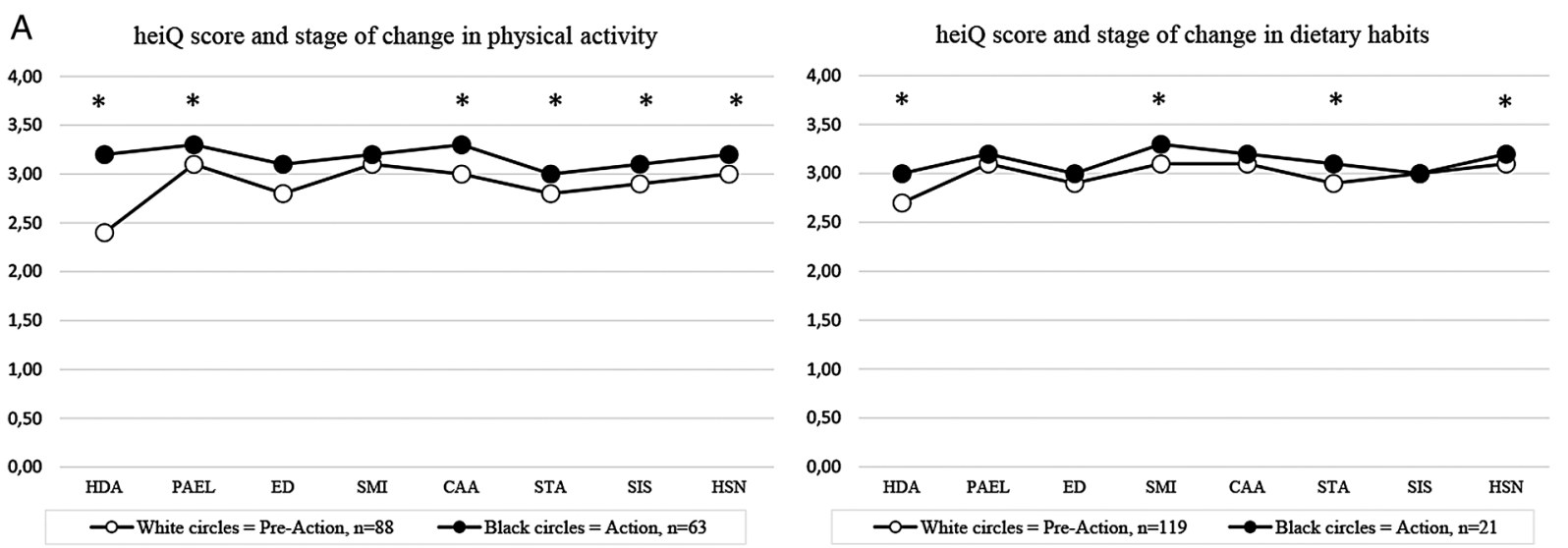

Median values adjusted for age, gender and education $* \mathrm{p}<0.005$

\begin{abstract}
HDA Health directed activity PAEL Positive and active engagement in life ED Emotional distress SMI Self-monitoring and insight
\end{abstract}

CAA Constructive attitude and approaches STA Skill and technique acquisition SIS Social integration and support HSN Health service navigation
B SF-36 score and stage of change in physical activity

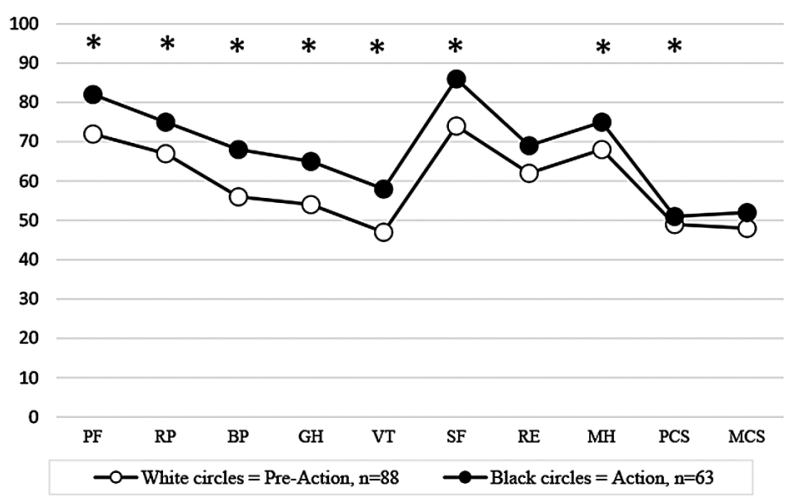

SF-36 score and stage of change in dietary habits

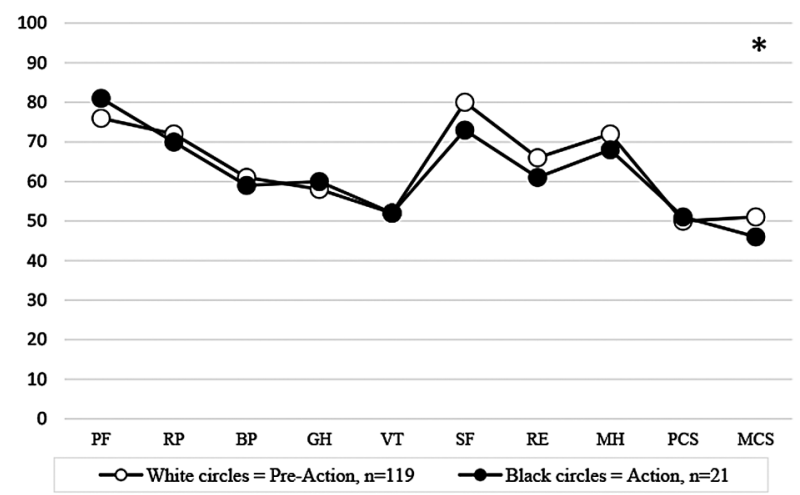

Median values adjusted for age, gender and education $* \mathrm{p}<0.005$

$\begin{array}{lll}\text { PF physical functioning } & \text { VT vitality } & \text { PCS physical component score } \\ \text { RP role physical } & \text { SF social functioning } & \text { MCS mental component score } \\ \text { BP bodily pain } & \text { RE role emotional } & \\ \text { GH general health } & \text { MH mental health } & \end{array}$

Figure 1 Stages of change for physical activity and dietary habits and associations with self-management scores (A) and HRQL scores (B). heiQ, Health Education Impact Questionnaire; HRQL, health-related quality of life; SF-36, short form 36.

Self-reported physical activity and low symptoms of depression $(<16)$ were positively associated with being in the action stage for physical activity change (table 4 ).

A higher intake of greens was associated with a higher probability of being in the action stage for dietary change (table 4).

\section{DISCUSSION}

The current paper describes stages of change in physical activity and dietary habits among persons with type 2 diabetes included in an mHealth trial. We found that being in the action stage for physical activity change and dietary change both were associated with a higher selfmanagement score. Moreover, being in the action stage for physical activity change was also associated with a higher HRQL and a lower risk for depressive symptoms.
Interestingly, being in the action stage for dietary change was associated with a lower mental HRQL. Forty-two per cent of the participants were in the action stage for physical activity change and only $21 \%$ in the action stage for dietary change. We also found an association between action for dietary change and action for physical activity change. Further, the participants in this sample had a high disease burden, as reflected by overweight and obesity, comorbidities, and high diabetes medication use; however, only BMI was significantly different between the preaction and the action stages for physical activity change.

Not surprisingly, and according to the stages of change model, our data revealed that being in the action stage for physical activity change and dietary change was associated with higher self-management scores. Possibly, individuals who are ready to change 
have greater self-management skills because they perform more actions to maintain good health. Self-management is crucial in persons with type 2 diabetes, ${ }^{4} 18$ and being successful at changing may improve self-management skills and ease daily living. ${ }^{8}$ The selfmanagement measure hei $Q^{33} 34$ has not earlier been used in combination with the stages of change model in an mHealth study, but this measure was sensitive to differences between the preaction and action stages. The significant associations between being in the preaction stage and having a lower level of self-management, as measured by the heiQ suggests the need to encourage change and progress toward the desired behavior. ${ }^{4} 36$ This may indicate that more advanced support is needed from healthcare personnel in this group.

Another finding of interest was that persons in the action stage for dietary change had lower scores in mental HRQL compared to the preaction group, which also has been described in earlier research. ${ }^{10}$ This suggests that the action stage may be a time of change that negatively affects HRQL and that changing dietary habits may be mentally demanding. The negative impact of change on HRQL was not apparent for physical activity change. It is possible that the threshold for changing physical activity is lower and relates to fewer negative emotions compared with dietary change. Dietary habits is a complex behavior, ${ }^{13}$ and a qualitative study found that patients' stages of change varied in different dietary areas and within certain dietary habits. ${ }^{14}$ This represents a challenge both for the staging of behavior change and for making a dietary change. Preparation and action tend to be the two busiest stages where much support is needed $;{ }^{13}$ however, it has earlier been shown how support from family and friends may be lower in the action stage for dietary change in persons with type 2 diabetes using insulin. ${ }^{10}$ It is possible that family and friends affected by the dietary change express negative emotions if they feel they are involved in the change without influence. Diets and type 2 diabetes are frequent topics in the media, ${ }^{37}$ and less nuanced headlines can create uncertainty regarding recommendations, which may foster negative emotions and stress related to the diet and make the dietary change more difficult. Being in the action stage for physical activity change was associated with higher HRQL scores. Our findings are consistent with earlier research that found a positive correlation between progressing through the stages of exercise change and an increase in HRQL. ${ }^{16}$ Our self-reported measures of physical activity level in the present study confirmed that those who report being in the action stage for physical activity change are more likely to engage in regular physical activity, meaning that those in the action stage for physical activity are physically more active compared to those in the preaction stage.

In our study, $>90 \%$ of the participants reported being overweight or obese. These findings are supported by earlier research that has reported that most people
$(80 \%)$ with type 2 diabetes are overweight or obese. ${ }^{38}$ In our study, we found that those in the preaction stage for physical activity had a higher BMI, compared to those in the action stage. Individuals struggling with overweight frequently report emotional problems and a low HRQL $^{39}$ decreasing with increased body weight. The overall high frequency of comorbidities among the participants and the use of injection or combination therapy for diabetes reflect the complex treatment received by such patients. ${ }^{45} 38$ The median duration of type 2 diabetes of 9 years suggests that the treatment may differ between those with long-term diabetes and newly diagnosed patients. ${ }^{38}$ Another finding of interest was the association between a lower score for depressive symptoms when in the action stage for physical activity change compared to the preaction stage, indicating that depressive symptoms may interfere with the ability to change health behavior. There were no differences in depressive symptoms between the participants in the preaction and action stages for dietary change.

Most of the participants placed themselves in the preaction stage for behavior change. This finding is consistent with other studies, ${ }^{7}{ }^{15}$ and may indicate a need to provide more continual support for self-management. ${ }^{4}$ We had expected more participants to be in the action stage because they had agreed to participate in an intervention study. ${ }^{40}$ Earlier research has described how people interested in a telehealth platform for diabetes self-management differ from the general population with diabetes. ${ }^{41}$ In addition, patient preferences should be accounted for, ${ }^{42}$ especially in trials involving mobile tools for self-management. However, stages of change in lifestyle and participation in a treatment intervention may represent different aspects, whereby the latter may be a result of the interactions between the patient, the clinician, and the environment. ${ }^{43}$ Stages of change in the two behaviors assessed were associated, and this finding is supported by earlier research, suggesting that a person is more likely to be in a higher stage for different behaviors at the same time. ${ }^{9}$ Positive change is more likely to occur when the individual is ready to change in the mid-stages ${ }^{78}$ and by building on previous successful changes, the person's readiness to further change may increase. ${ }^{8}$ However, the factors that drive change are debated. Some argue that change is not always a conscious act ${ }^{44}$ and may rather result from a trigger in a person who is not ready to change. ${ }^{36}$ Stages of change and readiness to change are often used interchangeably in the literature; however, readiness to change may need more context to be applicable to both those in preaction and action. Readiness to change should imply that the person has not yet changed; that is, would be in preaction. Stages of change would include preaction stages as well as action stages. The transtheoretical model has improved staging behavior and future work should focus on those not in the action stage, such as the majority of persons in this study. It is also debatable whether the stages of change construct are sensitive enough to 
distinguish the different stages in a real-life setting because people move between stages and there is no standardized measure. ${ }^{16} 43{ }^{44}$ We therefore merged the three preaction stages into one group (preaction) and the two action stages into another (action).${ }^{10}$ We found that being in the action stage was associated with greater self-management and HRQL, somewhat confirming the idea that those in the action stage perform more to maintain good health, and also strengthening the argument of why healthcare personnel should strive to help people change and move up the stages of change.

The current results may be prone to volunteer bias and self-selection, and the use of mainly self-reported measures necessitates caution in the interpretation of our findings. We anticipated that participants in an intervention study would mainly be in the action stage for change. However, this was not the case, although most of those interested in participating in this trial wished to receive the intervention, which was mHealth either alone or in combination with health counseling. Personal interest is important to participation in interventions using technology to promote behavioral change because of the focus on lifestyle changes and the use of the technology tools provided. ${ }^{21} 4142$

It is possible that those with poor metabolic control may be more amenable to telehealth interventions. ${ }^{41}$ The participants in this study had excessive weight, as well as increased HbAlc level and comorbidities, which indicates the need for changes. The associations between glycemic control and HRQL, ${ }^{3}$ and between HRQL, mortality, and the ability to work, ${ }^{6}$ mean that the complexity of diabetes management is an issue for the society, not just the individual. Lower socioeconomic status is associated with type 2 diabetes, and physical inactivity and obesity are more common among patients from a lower socioeconomic status. ${ }^{45}$ Disadvantaged populations (low income, older adults, ethnic minorities, etc) are, however, less likely to be included in studies of mHealth, although it is known that these populations are frequent mobile technology users and that research on this group is important as well. ${ }^{45}$

In conclusion, we have reported the baseline characteristics of a group of people with diabetes who participated in an mHealth intervention to address lifestyle changes that are not unique to persons with type 2 diabetes. For both physical activity and dietary habits, we have found that being in the action stages is associated with higher self-management, and being in the action stage for physical activity is associated with a lower BMI. Being in the action stages for dietary change is, however, associated with a lower HRQL, and special attention is needed for this group. Overall, we believe that moving people up the stages of change is positively associated with important parts of daily diabetes management, and should be given more attention in the future. The prospects of dealing with an ever older population with type 2 diabetes and comorbidities in the future is overwhelmingly related to the increased strain on the healthcare system, which will require a large amount of effort from both the national and local healthcare systems. Both patients and society are in need of strategies to prevent the negative outcomes related to the insufficient treatment of people with type 2 diabetes. ${ }^{2}{ }^{5}$ Further research with a greater overall perspective may be important.

Author affiliations

${ }^{1}$ Faculty of Health Sciences, Department of Nursing and Health Promotion, Oslo and Akershus University College of Applied Sciences, Oslo, Norway

${ }^{2}$ Faculty of Medicine, Department of Health Sciences, Institute of Health and Society, University of Oslo, Oslo, Norway

${ }^{3}$ Faculty of Medicine, Department of General Practice, Institute of Health and Society, University of Oslo, Oslo, Norway

Acknowledgments The authors thank the participants, their general practitioners, the leaders at the local public healthcare clinics, diabetes specialist nurse Tone Singstad (for delivering health counseling), and nutritionist Elisabeth Elind for making this study possible. The author also thank the project manager in the Norwegian pilot, Astrid Grottland, researcher Eirik Årsand, Elisabeth Ellefsen Sjaaeng, and Erlend Bønes at the Norwegian Centre of Integrated Care and Telemedicine for support during the study period.

Contributors $\mathrm{HH}$ collected and analyzed the data, as well as wrote and reviewed the manuscript. AW reviewed the manuscript. AT collected and analyzed the data, as well as reviewed the manuscript. AKJ reviewed the manuscript. MCS analyzed the data and reviewed the manuscript. LR collected and analyzed the data, as well as reviewed the manuscript. All authors have approved the final manuscript.

Funding This project was funded by the European Union through the ICT Policy Support Programme, as part of the Competitiveness and Innovation Framework Programme (CIP), and by the Norwegian Research Council. This project was also funded by the Health Authorities of Northern Norway, the Norwegian Centre of Integrated Care and Telemedicine at the University Hospital of North Norway, the Oslo and Akershus University College, the Akershus University Hospital, and the Norwegian Diabetes Association.

Competing interests None.

Ethics approval The Regional Ethics Committee South East in Norway.

Provenance and peer review Not commissioned; externally peer reviewed.

Data sharing statement There are still unpublished data available for persons of the research team in the Norwegian Study in RENEWING HEALTH. However, we have published our findings according to the ClinicalTrials registration.

Open Access This is an Open Access article distributed in accordance with the Creative Commons Attribution Non Commercial (CC BY-NC 4.0) license, which permits others to distribute, remix, adapt, build upon this work noncommercially, and license their derivative works on different terms, provided the original work is properly cited and the use is non-commercial. See: http:// creativecommons.org/licenses/by-nc/4.0/

\section{REFERENCES}

1. American Diabetes A. Standards of medical care in diabetes-2014. Diabetes Care 2014;37(Suppl 1):S14-80.

2. Schram MT, Baan CA, Pouwer F. Depression and quality of life in patients with diabetes: a systematic review from the European depression in diabetes (EDID) research consortium. Curr Diabetes Rev 2009;5:112.

3. Zhang X, Norris SL, Chowdhury FM, et al. The effects of interventions on health-related quality of life among persons with diabetes: a systematic review. Med Care 2007;45:820-34.

4. Powers MA, Bardsley J, Cypress M, et al. Diabetes self-management education and support in type 2 diabetes: a joint position statement of the American Diabetes Association, the American Association of Diabetes Educators, and the Academy of Nutrition and Dietetics. Diabetes Educ 2015;41:417-30. 
5. Claudi T. Nasjonale faglige retningslinjer: diabetes_Forebygging, diagnostikk og behandling [National Professional Guidelines for Prevention, Diagnostics and Treatment of Diabetes]. Oslo: Helsedirektoratet, 2009.

6. Bjorner JB, Wolden ML, Gundgaard J, et al. Benchmarks for interpretation of score differences on the SF-36 health survey for patients with diabetes. Value Health 2013;16:993-1000.

7. Prochaska JO, DiClemente CC, Norcross JC. In search of how people change: applications to addictive behaviors. Am Psychol 1992;47:1102-14.

8. Ruggiero LP, James O. Readiness for change: application of the transtheoretical model to diabetes. Diabetes Spectr 1993;6:22-60.

9. Bawadi HA, Banks AD, Ammari F, et al. Stage of change of 6 health-related behaviors among patients with type 2 diabetes. Prim Care Diabetes 2012;6:319-27.

10. Vallis M, Ruggiero L, Greene G, et al. Stages of change for healthy eating in diabetes: relation to demographic, eating-related, health care utilization, and psychosocial factors. Diabetes Care 2003;26:1468-74.

11. Jones H, Edwards L, Vallis TM, et al. Changes in diabetes self-care behaviors make a difference in glycemic control: the diabetes stages of change (DiSC) study. Diabetes Care 2003;26:732-7.

12. Salmela S, Poskiparta M, Kasila K, et al. Transtheoretical model-based dietary interventions in primary care: a review of the evidence in diabetes. Health Educ Res 2009;24:237-52.

13. Greene GW, Rossi SR, Rossi JS, et al. Dietary applications of the stages of change model. J Am Diet Assoc 1999;99:673-8.

14. Kasila K, Poskiparta M, Karhila P, et al. Patients' readiness for dietary change at the beginning of counselling: a transtheoretical model-based assessment. J Hum Nutr Diet 2003;16:159-66.

15. Natarajan S, Clyburn EB, Brown RT. Association of exercise stages of change with glycemic control in individuals with type 2 diabetes. Am J Health Promot 2002:17:72-5.

16. Andrés A, Gómez J, Saldaña C. Challenges and applications of the transtheoretical model in patients with diabetes mellitus. Dis Manag Health Outcomes 2008;16:31.

17. Noar SM, Benac CN, Harris MS. Does tailoring matter? Meta-analytic review of tailored print health behavior change interventions. Psychol Bull 2007;133:673.

18. Norris SL, Lau J, Smith SJ, et al. Self-management education for adults with type 2 diabetes: a meta-analysis of the effect on glycemic control. Diabetes Care 2002;25:1159-71.

19. Avery L, Flynn D, van Wersch A, et al. Changing physical activity behavior in type 2 diabetes: a systematic review and meta-analysis of behavioral interventions. Diabetes Care 2012;35:2681-9.

20. Marcolino MS, Maia JX, Alkmim MBM, et al. Telemedicine application in the care of diabetes patients: systematic review and meta-analysis. PLOS ONE 2013;8:e79246.

21. Garabedian LF, Ross-Degnan D, Wharam JF. Mobile phone and smartphone technologies for diabetes care and self-management. Curr Diab Rep 2015;15:109.

22. Torbjørnsen A, Jenum AK, Småstuen MC, et al. A low-intensity mobile health intervention with and without health counseling for persons with type 2 diabetes, Part 1: baseline and short-term results from a randomized controlled trial in the Norwegian part of RENEWING HEALTH. JMIR Mhealth Uhealth 2014;2: e52.

23. Holmen $\mathrm{H}$, Torbjørnsen $\mathrm{A}$, Wahl $\mathrm{AK}$, et al. A mobile health intervention for self-management and lifestyle change for persons with type 2 diabetes, Part 2: one-year results from the Norwegian randomized controlled trial RENEWING HEALTH. JMIR Mhealth Uhealth 2014;2:e57.
24. Ribu L, Holmen H, Torbjørnsen A, et al. Low-intensity self-management intervention for persons with type 2 diabetes using a mobile phone-based diabetes diary, with and without health counseling and motivational interviewing: protocol for a randomized controlled trial. JMIR Res Protoc 2013;2:e34.

25. RenewingHealth. Assessment method: Renewing Health; (cited 30 May 2014). http://www.renewinghealth.eu/en/assessment-method

26. Lorentzen C, Ommundsen Y, Holme I. Psychosocial correlates of stages of change in physical activity in an adult community sample. Eur J Sport Sci 2007:7:93-106.

27. Prochaska JO, Marcus BH. The Transtheoretical Model: Applications to Exercise. In: Dishman RK ed. Advances in Exercise Adherence. Champaigne, IL: Human Kinetics, 1994:161-80.

28. NTNU. The HUNT study - a longitudinal population health Study in Norway. Nord-Trøndelag Health Study [Web-page] (cited 25 November 2013). http://www.ntnu.edu/hunt

29. Kurtze N, Rangul V, Hustvedt BE, et al. Reliability and validity of self-reported physical activity in the Nord-Trøndelag Health Study (HUNT 2). Eur J Epidemiol 2007;22:379-87.

30. Larsen IK, Grotmol T, Almendingen K, et al. Impact of colorectal cancer screening on future lifestyle choices: a three-year randomized controlled trial. Clin Gastroenterol Hepatol 2007:5:477-83.

31. Ware JE, Jr. SF-36 health survey update. Spine 2000;25:3130-9.

32. Loge JH, Kaasa S, Hjermstad MJ, et al. Translation and performance of the Norwegian SF-36 Health Survey in patients with rheumatoid arthritis. I. Data quality, scaling assumptions, reliability, and construct validity. J Clin Epidemiol 1998;51:1069-76.

33. Osborne RH, Elsworth GR, Whitfield K. The Health Education Impact Questionnaire (heiQ): an outcomes and evaluation measure for patient education and self-management interventions for people with chronic conditions. Patient Educ Couns 2007;66:192-201.

34. Osborne RH, Batterham R, Livingston J. The evaluation of chronic disease self-management support across settings: the international experience of the health education impact questionnaire quality monitoring system. Nurs Clin North Am 2011;46:255-70.

35. Radloff $L$. The CES-D scale: a self-report depression scale for research in the general population. Appl Psychol Meas 1977;1:385

36. Peyrot M, Rubin RR. Behavioral and psychosocial interventions in diabetes: a conceptual review. Diabetes Care 2007;30:2433-40.

37. Gollust SE, Lantz PM. Communicating population health: print news media coverage of type 2 diabetes. Soc Sci Med 2009;69:1091-8.

38. Inzucchi SE, Bergenstal RM, Buse JB, et al. Management of hyperglycemia in type 2 diabetes: a patient-centered approach: position statement of the American Diabetes Association (ADA) and the European Association for the Study of Diabetes (EASD). Diabetes Care 2012:35:1364-79.

39. Kolotkin R, Meter K, Williams G. Quality of life and obesity. Obes Rev 2001;2:219-29.

40. Adamson SJ, Bland JM, Hay EM, et al. Patients' preferences within randomised trials: systematic review and patient level meta-analysis. BMJ 2008;337:a1864

41. Buysse H, De Moor G, Coorevits P, et al. Main characteristics of type 1 and type 2 diabetic patients interested in the use of a telemonitoring platform. J Nurs Healthc Chronic IIIn 2011;3:456-68.

42. Brewin $\mathrm{CR}$, Bradley $\mathrm{C}$. Patient preferences and randomised clinical trials. BMJ 1989;299:313-15.

43. Littell JH, Girvin H. Stages of change: a critique. Behav Modif 2002;26:223-73.

44. West R, Brown J. Theory of addiction. John Wiley \& Sons, 2013.

45. Agardh E, Allebeck P, Hallqvist J, et al. Type 2 diabetes incidence and socio-economic position: a systematic review and meta-analysis. Int J Epidemiol 2011;40:804-18. 